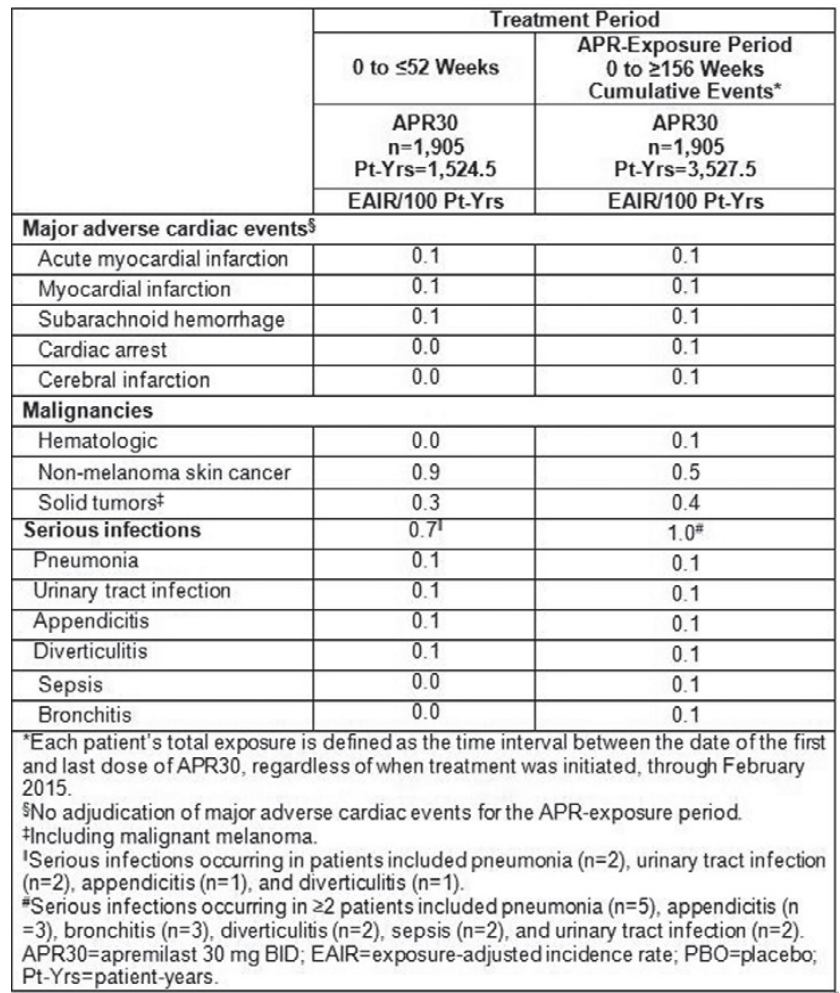

Conclusions: Incidence of MACE, malignancies, and SIs was low in pts with psoriasis and PsA receiving APR30 for $\geq 156$ wks. No new safety signals or SOls were observed over time with APR30.

Disclosure of Interest: A. Kavanaugh Grant/research support from: Abbott, Amgen, AstraZeneca, BMS, Celgene Corporation, Centocor-Janssen, Pfizer, Roche, and UCB, M. Augustin Consultant for: AbbVie, Almirall, Amgen, Biogen, Boehringer Ingelheim, Celgene Corporation, Centocor, Eli Lilly, GSK, JanssenCilag, LEO Pharma, Medac, Merck, MSD, Novartis, Pfizer, UCB, and XenoPort, Speakers bureau: AbbVie, Almirall, Amgen, Biogen, Boehringer Ingelheim, Celgene Corporation, Centocor, Eli Lilly, GSK, Janssen-Cilag, LEO Pharma, Medac, Merck, MSD, Novartis, Pfizer, UCB, and XenoPort, E. Lespessailles Grant/research support from: Amgen, Celgene Corporation, Eli Lilly, and Novartis, Speakers bureau: Amgen, Celgene Corporation, Eli Lilly, and Novartis, K. Papp Grant/research support from: AbbVie, Allergan, Amgen, Anacor, Astellas, Baxalta, Biogen-Idec, Boehringer Ingelheim, Bristol-Myers Squibb, Celgene Corporation, Dermira, Dow Pharma, Eli Lilly, Galderma, Genentech, Glenmark, GSK, Janssen, Kyowa Hakko Kirin, LEO Pharma, Medlmmune, Merck, Merck Serono, Mylan, Novartis, Pfizer, Regeneron, Roche, Sanofi-Aventis, Stiefel, Takeda, UCB, and Valeant, Consultant for: AbbVie, Akros, Allergan, Amgen, Anacor, Astellas, AstraZeneca, Baxalta, Baxter, Biogen-Idec, Boehringer Ingelheim, Bristol-Myers Squibb, Can-Fite BioPharma, Celgene Corporation, Celtic, Cipher, Dermira, Dow Pharma, Eli Lilly, Formycon, Forward Pharma, Funxional Therapeutics, Galderma, Genentech, Genexion, Glenmark, GSK, Janssen, Kyowa Hakko Kirin, LEO Pharma, Lypanosys, Medlmmune, Merck, Merck Serono, Mitsubishi Pharma, Mylan, Novartis, Novommune, Pan Genetics, Pfizer, Regeneron, Roche, SanofiAventis, Stiefel, Sun Pharma, Takeda, UCB, Valeant, Vertex, and Xoma, M. Paris Employee of: Celgene Corporation, R. Chen Employee of: Celgene Corporation, D. Gladman Grant/research support from: AbbVie, Amgen, BMS, Celgene Corporation, Janssen, Novartis, Pfizer, and UCB, Consultant for: AbbVie, Amgen, BMS, Celgene Corporation, Janssen, Novartis, Pfizer, and UCB, D. Pariser Grant/research support from: Abbott Laboratories, Amgen, Astellas Pharma US, Asubio Pharmaceuticals, Basilea Pharmaceutical, Celgene Corporation, Dow Pharmaceutical Sciences, Eli Lilly, Galderma Laboratories, Graceway Pharmaceuticals, Intendis, Johnson \& Johnson, Novartis Pharmaceuticals, Novo Nordisk A/S, Ortho Dermatologics, Photocure ASA, Stiefel Laboratories, and Valeant Pharmaceuticals, K. Peris Consultant for: Eli Lilly, LEO Pharma, MEDA, and Roche

DOI: 10.1136/annrheumdis-2017-eular.5065

\section{AB0744 DOES TIMING OF INITIATION OF ANTI-TNF AGENTS AFFECT THE QUALITY OF LIFE OUTCOMES IN PATIENTS WITH PSORIASIS AND PSORIATIC ARTHRITIS?}

P.W. Barnes ${ }^{1}$, N. Rich-Garg ${ }^{2}$, D. Choi ${ }^{3}$, A. Deodhar ${ }^{2} .{ }^{1}$ School of Medicine; ${ }^{2}$ Division of Arthritis \& Rheumatic Diseases; ${ }^{3}$ Public Health \& Preventative Medicine, Oregon Health and Science University, Portland, United States

Background: Psoriatic Arthritis (PsA) affects up to $30 \%$ of people with psoriasis ${ }^{1}$.
While Tumor Necrosis Factor inhibitors (TNFi) are effective agents for PsA, the relationship between early treatment and patient reported outcomes in a real world setting has not been reported previously.

Objectives: To assess whether timely treatment with TNFi leads to better improvement in quality of life outcomes than delayed treatment.

Methods: This was a retrospective analysis of patients with PsA and/or Psoriasis (PsO) using TNFi with or without methotrexate, and who had a minimum of 2 visits at the Center of Excellence for Psoriasis and Psoriatic Arthritis at our university. Detailed demographic and clinical characteristics of this cohort have been published previously ${ }^{2}$. Demographics, quality of life measures (e.g. Routine Assessment of Patient Index Data - RAPID3, Psoriasis Quality of Life - PQoL12, Short Form 12 - SF-12), and clinical data (percent of body surface area involved with $\mathrm{PsO}-\mathrm{BSA} \%$ ) were collected from patient-reported questionnaires and electronic medical records. Only those patients who had a chronological overlap of treatment exposure and QoL measures such as RAPID3, BSA, SF12 and PQOL were included. To ascertain treatment effects, a mixed-effects model was fitted to estimate the trend of each QoL outcome of a patient separately. Then, for all estimated trends of an outcome, a linear regression model was employed to explore the association between the magnitude of estimated trends and timeliness of TNFi treatments.

Results: The quality of life measures were not affected by how early after the disease onset TNFi treatment was started (in other words, no statistically significant associations between the effectiveness of TNFi treatment and disease duration) for RAPID3 ( $\mathrm{p}=0.285), \mathrm{SF}-12(\mathrm{p}=0.674)$, or $\mathrm{BSA}(\mathrm{p}=0.078)$. For PQoL, there was a significant association between the trend of treatment effects and timeliness of treatment. A day of delay into treatment was resulted in a reduction of $4.4 \times 10^{-4} /$ day in the trend of PQoL scores $(p=0.007)$.

Conclusions: In this sample of PsA \& PsO patients, timing of starting TNFi in patients with PsA had significant impact on improvements in the PQoL but not other quality of life measures such as RAPID3, SF-12 and BSA. A relatively short treatment history might have led to the negative correlations.

References:

[1] McLaughlin M, et.al. Early treatment of psoriatic arthritis improves prognosis. Practitioner 2014258 (1777) 21-24.

[2] Truong B et.al. Demographics, clinical disease characteristics and quality of life in a large cohost of psoriasis patients with and without psoriatic arthritis. Clin, Cosm and Inv Dermatology 2015: 8: 563-569.

Disclosure of Interest: None declared

DOI: 10.1136/annrheumdis-2017-eular.1535

\section{AB0745 SUBCLINICAL ATHEROSCLEROSIS EVOLUTION IN PSORIATIC ARTHRITIS PATIENTS TREATED WITH ANTI-TNF ALPHA: 5 YEARS FOLLOW UP}

A. Ortolan ${ }^{1}$, M. Puato ${ }^{2}$, G. Boschetti ${ }^{3}$, M. Lorenzin ${ }^{1}$, A. Hoxha ${ }^{1}$, L. Punzi ${ }^{1}$ R. Ramonda ${ }^{1} .{ }^{1}$ Rheumatology Unit, Department of Medicine DIMED, University of Padova; ${ }^{2}$ Clinica Medica III, Department of Medicine DIMED, Universityof Padova; ${ }^{3}$ Clinica Medica III, Department of Medicine DIMED, University of Padova, Padova, Italy

Background: Psoriatic arthritis (PsA) is associated with increased morbility and mortality and an accelerated atherosclerosis. Influence of anti-TNFalpha treatment (a widely used therapy in PsA) in subclinical atherosclerosis is still unclear.

Objectives: The aim of this study was to evaluate subclinical atherosclerosis progression before, during and after 5 years of anti-TNFalpha treatment.

Methods: Twenty-seven consecutive PsA patients were evaluated before TNF blockers therapy (T0), after 2 years (T1) and after 5 years (T2) of treatment. Subclinical atherosclerosis was evaluated through carotid duplex scanning, analyzing intima-media thickness (IMT) and flow-mediated dilation (FMD). IMT values were expressed as IMT mean (cumulative mean of all the IMT mean in every analyzed carotid segment) and M-MAX (cumulative mean of all the higher IMT in every analyzed carotid segment). Response to therapy was studied by the evaluation of tender and swollen joints (Tj and Sj), DAS 28 (disease activity score), erythrocyte sedimentation rate (ESR) and C-reactive protein (CRP). Metrologic and metabolic data were collected. For the statistical evaluation of parameters over time (T0 vs T1, T1 vs T2) Student's T test for paired data was used Results: From T0 to T1 a deterioration in IMT-mean and M-MAX $(p<0.01)$ was

Table

\begin{tabular}{|l|l|l|l|}
\hline & T0 & T1 & T2 \\
\hline IMT-mean & $0.72 \pm 0.15$ & $0.91 \pm 0.37^{*}$ & $0.92 \pm 0.34$ \\
\hline M-MAX & $0.89 \pm 0.18$ & $1.06 \pm 0.39^{*}$ & $1.10 \pm 0.35^{* *}$ \\
\hline FMD & $5.40 \pm 1.93$ & $5.37 \pm 1.66$ & $5.40 \pm 1.89$ \\
\hline Tender joints (n) & $8.10 \pm 5.56$ & $2.09 \pm 2.32^{*}$ & $1.72 \pm 2.05$ \\
\hline Swollen joints (n) & $3.85 \pm 3.84$ & $0.25 \pm 0.72^{*}$ & $0.50 \pm 0.92$ \\
\hline CRP & $11.25 \pm 9.16$ & $2.91 \pm 1.72^{*}$ & $2.73 \pm 2.51$ \\
\hline DAS28 & $4,16 \pm 0.67$ & $2.30 \pm 0.82^{*}$ & $2.40 \pm 0,9$ \\
\hline
\end{tabular}

Legend: IMT= intima-media thickness; $\mathrm{M}-\mathrm{MAX}=$ cumulative mean of all the higher IMT in every analyzed carotid segment; $\mathrm{FMD}=$ flow-mediated dilation; $\mathrm{CRP}=\mathrm{C}$ Reactive Protein; DAS28=Disease Activity Score $28 j$ joints; ${ }^{*}=p<0.01$ with respect to the previous determination; ${ }^{* *}=\mathrm{p}<0.05$ with respect to the previous determination 